\title{
IES
}

\section{IDENTIFYING ANTI-TRUST MARKETS}

Paul Geroski
Rachel Griffith 


\title{
IDENTIFYING ANTI-TRUST MARKETS*
}

\author{
P.A. Geroski \\ London Business School \\ and \\ the Competition Commission \\ R. Griffith \\ Institute for Fiscal Studies \\ and \\ University College London
}

January, 2003

Forthcoming in M. Neumann and J. Weigand (eds), International Handbook of Competition, Edward Elgar, 2003.

* The views expressed in this paper are those of the authors alone and do not necessarily reflect those of the institutions - or any of the individuals in them - that they are affiliated with. We are obliged to Derek Morris and Geoffrey Sumner both for ongoing discussions as well as for comments on an earlier draft. The usual disclaimer applies. 


\section{EXECUTIVE SUMMARY}

The identification of markets is a standard feature of anti-trust investigations, and the substantive decision in many cases stands or falls on the precise market definition selected. Market shares are often used to help establish jurisdiction or, more generally, to sort out priorities for anti-trust agencies. Market shares are also sometimes used as an observable measure of market power, meaning that the fact of finding high market shares is sometimes taken to be tantamount to uncovering the existence of market power.

The standard test used by most anti-trust authorities to define markets is the socalled SSNIP test (sometimes also called "the hypothetical monopolist test"), which is designed to explore the consequences of a (hypothetical) Small but Significant Non-transitory Increase in Price on the profitability of the (hypothetical) firm that initiates it. At the heart of this test is the question of what might make such a price rise unsustainable. When the hypothetical monopolist raises it's prices, it will lose some sales as at least some consumers choose not to purchase the product at all and drop out of the market. However, it will also lose sales for two other reasons: some consumers will switch to substitute products ("demand side substitutability") and some firms operating "near" to the (narrowly defined) candidate market will alter their production programmes and supply similar products to other consumers in the market at lower prices ("supply side substitutability"). If there are close demand or supply side substitutes, then the price increase initiated by the hypothetical monopolist will lead to a large reduction in it's sales, and it's profits will, as a consequence, fall.

A number of difficulties arising in identifying market boundaries, and it sometimes requires fairly finely tuned judgements to do the exercise properly. Four particular areas of difficulty are: dealing with intermediate goods markets, applying to tests to markets that are already monopolised (know as the cellophane fallacy), determining what is small but significant and deciding how to treat firms that operate in many related markets. This paper briefly discusses how these problems are tackled in practice

The SSNIP test enables us to identify the relevant market for the purposes of analysis but that is just the start of any anti-trust inquiry. The real issue in every case is not what the market is, but how competitive it is (or how a merger affects competition). There are three features of the market - however defined - which determine it's competitiveness and they are: the degree of intra-market rivalry, the extent of buyer (or supplier) power, and the state of entry. In order to assess these it is important to have a clear definition of the markets involved. 


\section{WHY DEFINE MARKETS?}

The identification of markets is a standard feature of anti-trust investigations, and the substantive decision in many cases stands or falls on the precise market definition selected. Market identification is important because the computation of market shares matters in antitrust cases, and this is so for at least two reasons. First, market shares are often used to help establish jurisdiction or, more generally, to sort out priorities for anti-trust agencies. Merger regulations usually specify a threshold level of market share which triggers an investigation for mergers above a given size; investigations into various monopolistic abuses are usually centred on the leading firms in a market, and, in most cases, the ability of an anti-trust agency to initiate an investigation, or impose penalties at the end of it, depends on whether the (alleged) offending firm enjoys a position of market "dominance"; i.e. enjoys a large market share. Second, market shares are sometimes used as an observable measure of market power, meaning that the fact of finding high market shares is sometimes taken to be tantamount to uncovering the existence of market power. Since, in practice, the important step in computing market shares is ascertaining the boundaries of the market, this practice tends to make the determination of market boundaries the substantively important decision in any attempt to identify pockets of market power.

The use of market shares to establish jurisdiction is a well established procedure. It is based on the relatively uncontroversial notion that firms with small market shares are unlikely to do much damage to either consumers or to their rivals if they behave uncompetitively. However, the converse - that firms with large market shares will necessarily have the power to force through price rises or exclude rivals from the market - is not necessarily true (however plausible it might seem as a presumption). A firm with a large market share whose customers were (somehow) locked in to purchasing from it come what may for a long period of time might well be deemed to have market power. If, on the other hand, it's customers are mobile if they can easily switch to rival's products or can easily be poached by rival suppliers - then it is likely that such power will evaporate in any attempt to use it. In this case, a firm might enjoy a high market share without enjoying much (if any) market power. To put the same point a different way, it is difficult to accept the proposition that market shares necessarily identify pockets of market power in the absence of an analysis of the full set of competitive forces that operate in the market. Since it is impossible to talk sensibly about "the full set of competitive forces that operate in the market" without having a fairly clear definition of what that market is, it is clear that identifying market boundaries must be the first step taken in the assessment of competition. It cannot, however, be the final step.

Thus, defining the market and identifying which firms operate within that market should be (and is) a central feature of anti-trust investigations. There is, however, a second step which needs to follow any identification of market boundaries, and that is an assessment of how competitive that market actually is. This distinction is, of course, much easier to make conceptually than it is to do in practice: since identifying market boundaries effectively involves identifying the limits of substitution - on the demand and/or on the supply side - the process of evaluating competition and that of identifying market boundaries is, and will always be, inextricably intertwined. Nevertheless, the distinction is an important one, and we have organized what follows directly from it. In Sections II and III below, we discuss the standard method used by anti-trust authorities to identify market boundaries - the so-called SSNIP test and explore a number of the complications which arise when using it. In Section IV, we turn to 
the second step and briefly outline what is involved in assessing the competitiveness of a market. We conclude with a few final observations in Section V.

\section{THE SSNIP TEST}

The standard test used by most anti-trust authorities to define markets is the socalled SSNIP test (sometimes also called "the hypothetical monopolist test"), which is designed to explore the consequences of a (hypothetical) Small but Significant Non-transitory Increase in Price on the profitability of the (hypothetical) firm that initiates it. ${ }^{1}$ The test is effectively an iterative procedure, and works as follows:

- we start with the narrowest group of products and geographical area that is reasonable $;^{2}$

- we then suppose that these products sold in that area are wholly monopolized, and ask what would happen if that (hypothetical) monopolist were to raise it's prices by $10 \%$;

- if that price rise is not profitable, then we add the closest substitute product (or geographical area) to the (hypothetically) monopolized bundle, and repeat the procedure;

- the procedure stops when we find a collection of products sold in a particular area which, if monopolized, would sustain a price rise of $10 \%$ by that monopolist.

Although it all seems simple enough, there are at least four aspects of this procedure that are worth a closer look.

First, at the heart of this test is the question of what might make such a price rise unsustainable. Clearly, when the hypothetical monopolist raises it's prices, it will lose some sales as at least some consumers choose not to purchase the product at all and drop out of the market. However, it will also lose sales for two other reasons: some consumers will switch to substitute products ("demand side substitutability") and some firms operating "near" to the (narrowly defined) candidate market will alter their production programmes and supply similar products to other consumers in the market at lower prices ("supply side substitutability"). If there are close demand or supply side substitutes, then the price increase initiated by the hypothetical monopolist will lead to a large reduction in it's sales, and it's profits will, as a consequence, fall. ${ }^{3}$ The iterative procedure outlined above selects the closest of these supply or demand side substitutes at each stage of the process and adds them to the candidate market

\footnotetext{
${ }^{1}$ See USDOJ (1992); EC (1997), OFT (1999b, 2001), Competition Commission (2002).

${ }^{2}$ In the case of a merger, for example, this is likely to include the principal products and areas of operation of the two firms - or at least those most directly affected by the merger.

${ }^{3}$ That is, the existence of close demand or supply substitutes will make the demand curve facing the hypothetical monopolist - sometimes called it's "residual demand" - more elastic than market demand. Clearly, the more elastic is it's residual demand, the less likely it is that a price rise will be profitable.
} 
definition being considered at that stage. The process ends when the addition of the marginal demand or supply side substitute does not affect the ability of the hypothetical monopolist to profit from a price rise.

To understand how large the volume fall-off has to be to make the hypothesized price rise unsustainable, it is necessary to consider costs. If all costs were fixed, then a $10 \%$ price rise that reduced volume sold by about $10 \%$ would leave both revenue and costs unchanged, and, therefore, it would have no effect on profits. ${ }^{4}$ Hence, if all costs are fixed, any volume decrease larger than $10 \%$ would necessarily reduce revenues and, therefore, profits. If some costs are variable, then the decrease in volume caused by the hypothetical price rise will also lead to a reduction in costs, and, hence, a volume fall of more than $10 \%$ in volume may still be consistent with an increase in profits following the hypothesized price rise. It turns out that the critical volume decrease which separates a profitable from an unprofitable price rise depends on the prevailing price - marginal cost margin ${ }^{5}$ that is being earned at the price from which the experiment starts (see the appendix for details): the smaller is that price-marginal cost margin (i.e. the closer to zero it is), the larger the volume fall-off has to be to make the hypothetical monopolist's price rise unsustainable. When all costs are fixed, the price-marginal cost margin is unity, and, as we have just seen, a volume drop-off of just over $10 \%$ will reduce profits.

Second, the starting point of the SSNIP test is "the narrowest groups of products and geographical area that is reasonable". In practice, many firms involved in anti-trust investigations operate in more than one market because they produce a wide range of goods. This usually means starting with a subset of the goods produced by the firm or firms whose behaviour (or proposed merger) is the centre of interest, and the process of adding the closest supply and demand side substitutes effectively identifies the most powerful competitive (i.e. demand or supply side) constraints put on that firm (using the $10 \%$ rule as a way of measuring how powerful they really are). The first bundle of activities added to the initial hypothetical monopoly are those most likely to undermine any attempt to exploit that monopoly; the second bundle are those next most likely, and so on. The importance of starting from a narrow initial definition is that the market boundaries eventually established by the procedure do not include products, geographical areas or suppliers who do not compete directly with each other. If this approach sins, it does so by omitting relevant products, areas and firms from the market. One consequence of this is that the SSNIP test almost always ends up with narrower market definitions than those in popular use, and many SSNIP markets populate sectors like "telecommunications", "pharmaceuticals" and so on. From the anti-trust authorities point of view this is probably the correct direction in which to err. If the market is defined too narrowly, so that market shares overstate a firms market power, this will become apparent in the competition tests. On the other hand, if markets were defined too broadly, so market shares were understated, this might lead to firms with potential market power not being investigated.

Third, one of the challenges of applying the SSNIP test is its hypothetical nature and gathering the information needed to put it in to practice. It is almost always the case that one cannot directly observe a SSNIP test in operation. It is rare to find a "natural experiment" in which a monopolist unilaterally pushes through a $10 \%$ price rise to see what will happen. In

\footnotetext{
${ }^{4}$ Strictly speaking, the fall off need only be $9.1 \%$. Initially, profits are $\pi_{0}=\mathrm{p} * \mathrm{q}$. When price rises to $1.1 \mathrm{p}$, profits become $\pi_{1}=1.1 \mathrm{p}^{*}(1-\mathrm{x}) \mathrm{q}$ when quantity falls by $\mathrm{x}$. Profits remain unchanged if $\pi_{0}=\pi_{1}$; i.e. when $\mathrm{x}=0.91$.

${ }^{5}$ The price-marginal cost margin is price minus marginal cost over price.
} 
practice the sort of information that is used includes estimates of the parameters of a demand system (in particular the own and cross price elasticities), information on product

characteristics and consumer preferences (gathered either from industry sources or consumer surveys), information on past price movements and information on product technologies and costs. As a consequence, calculating the outcome of applying the SSNIP test almost always involves making indirect inferences, and the answers which emerge almost always contain some degree of imprecision. There is a burgeoning literature which explores various methodologies (including econometric models and conjoint analysis) which might be used to help make these inferences. ${ }^{6}$

Finally, it is worth stepping back and putting all of this into perspective. The basic idea behind the SSNIP test is that a market is a collection of products and geographical areas which can be profitably monopolized. This is a natural way for anti-trust authorities to think about market definitions, since what is of concern in anti-trust cases is the incentives that firms have to create and exploit monopoly positions. However, it is not quite the same as the way of thinking about markets as that which features in the traditional approach to market definition entombed in first year economics textbooks. That approach to identifying markets is often called the "law of one price", and tests based on it attempt to identify an area in which arbitrage operates to eliminate price differences between identical products. ${ }^{7}$ In a sense, it identifies what might be called "a trading market" - an area within which it will be impossible for a trader to sustain a price for the products of interest that is different from those prevailing elsewhere in the same area. The law of one price differs from the SSNIP test in at least two ways: it relies on the technology of arbitrage to set overall market boundaries and it typically concentrates only on demand side substitution. In general, there is no obvious relationship between the market boundaries identified by using tests based on the law of one price and those identified by using the SSNIP test. ${ }^{8}$

\section{SOME COMPLICATIONS}

Identifying market boundaries is as much an art as it is a science, and it sometimes requires fairly finely tuned judgements to do the exercise properly. There are a number of areas where there is a need for such judgements, and we discuss four of these in what follows.

\section{intermediate goods markets}

When a product is an intermediate good, and not sold direct to consumers, there are two transactions of interest: the retail transaction (between retailers and final consumers) and

\footnotetext{
${ }^{6}$ See, inter alia, Kovacic (1997), Baker and Rubinfeld (1999); the Competition Commission has begun to use consumer surveys to help quantify consumer reactions to a hypothetical price rise in particular markets.

${ }^{7}$ There is a large literature on tests involving the law of one price. The most common approaches involve looking at price differences between different regions for the same or similar products, looking for correlations between price changes over time, or tracking trade flows. For further discussion, see Sheffman and Spiller (1987), Geroski, (1998), Slade (1986), Baker and Bresnahan (1985), Fisher (1987), Hausman et al (1996), Forni (2002) and others.

${ }^{8}$ This said, price correlation tests have been used by anti-trust bodies as evidence on market definition; see, inter alia, OFT (1999a), Steen and Salvanes (1999), and others.
} 
the wholesale transaction (between the manufacturer and the retailer). ${ }^{9}$ If the market of interest is the wholesale market, then it is clear that the consequences of a $10 \%$ increase in wholesale prices will depend, in part, on behaviour in the downstream retail market. The two issues of importance here are: the degree of pass through (i.e. the extent to which retailers pass all of the $10 \%$ rise in wholesale prices on to their customers), and the extent of consumer reaction to whatever percentage price rise actually is passed through. The responses of consumers will condition the action of retailers and, in effect, shape their demand at the wholesale level for the product.

The analysis becomes more complicated when the manufacturer is vertically integrated downstream, retailing (at least part of it's output) direct to consumers. In this situation, it clearly competes with retailers and this observation is sometimes used to argue that the wholesale and retail markets are effectively one single market. The SSNIP test applied to such a market effectively asks what might happen to a vertically integrated monopolist who produces and sells all of the output produced in the candidate market. While this may be an interesting question to ask, it tells us nothing of substance about the wholesale market taken on it's own (or, for that matter, the retail market). Further, it is (arguably) sloppy practice. The SSNIP test starts from the narrowest market definition, and in this case that must mean the wholesale market or the retail market taken on it's own. Further, it should not be the case that market definitions depend on how firms choose to organize their activities: that a firm chooses to vertically integrate forward does not necessarily mean that wholesale and retail markets are just one big market.

\section{the cellophane fallacy}

A monopolist will set prices at the point where consumers are just on the margin of switching to some other product or of dropping out of the market altogether. This is where profits are maximised. This means that when monopoly prices prevail in the market, there will appear to be many substitutes for the monopolists product. However, the fact that there appear to be many substitutes at this price does not mean that this is not a monopoly price - indeed, if there were no apparent substitutes at a particular market price, one would be tempted to conclude that that price was not being set at monopoly levels. The implication of this observation is that that the appearance of substitutes at prevailing prices does not necessarily mean that they should be included in the same market. This observation has come to be known as the "cellophane fallacy" after a famous US anti-trust case against Du Pont. Du Pont argued that cellophane was not a separate market, since at prevailing prices there appeared to be a high cross elasticity of demand between cellophane and aluminium foil, wax paper and polyethylene. This meant that what seemed to be a near monopoly of "the cellophane market" looked like a much more modest share of something that might be called "the wrappings market" (or so the judge in the case thought).

The right way to avoid the cellophane fallacy depends on the kind of case that one is concerned with. In a merger case, one is typically concerned with whether the merger is going to enhance the firm's market position in a way which might be abused. The question of interest, then, is whether the firms involved in the merger are likely to be able raise prices as a result of the merger and earn higher profits. To answer this question is seems natural to apply

\footnotetext{
${ }^{9}$ There may, in fact, be more transactions if one or more independent wholesalers is involved in the value chain.
} 
the SSNIP test to existing market prices. That is, to ask whether, as a consequence of the merger, a 10\% increase in prices above the current level can be sustained by the merged firm. If so, the merger will clearly enhance the firm's market power; if not, then the market that the merged firms operate in must include other products, areas and/or suppliers, and it's competitiveness must be assessed when it's exact boundaries have been ascertained (see Section IV below). In a so-called monopoly inquiry, where one is exploring whether one or more firms have, or have abused, a monopoly position, it seems unwise to use prevailing market prices as the basis from which to consider a hypothetical $10 \%$ price rise since there is at least a chance that those prices will already reflect an element of monopoly power. A better procedure is to start by ascertaining what level of prices might prevail were the market to be competitive, and then use that as the basis of the SSNIP test. If prevailing prices appeared to be sustainable and were $10 \%$ or more higher than this level, then it would follow almost immediately that the firm(s) in question had at least some market power.

\section{what is "small but significant"?}

It has become something of a convention to consider $10 \%$ to be a "small but significant" price rise. However, what is considered to be "small but significant" will vary across markets and over time and will depend on product characteristics, past price increases, current inflation rates and a number of other factors. The $10 \%$ convention was established at a time of rather high inflation, and many think it may be considered too high in times of lower inflation. These arguments usually result in the use of a test based on 5\% (e.g. see the Competition Commission, 2002). One way to think about the reasonableness (or otherwise) of $10 \%$ is as follows. Suppose that a competitive industry suddenly (somehow) becomes monopolized, and monopoly prices are set. If, prior to the monopolization, the market were competitive then prices would equal marginal costs; post the monopolization, price cost margins will rise, and, for the sake of argument, let us suppose that they end up at $10 \% .{ }^{10}$ Since the monopoly margin is equal to the reciprocal of the elasticity of demand, a $10 \%$ margin implies that demand is quite elastic, and one might feel that if a 10\% price rise is all the monopolist can engineer following his/her monopolization of the market, then that monopoly might be rather benign. If, however, the monopolist can engineer at least a $10 \%$ rise, this must mean that demand is much elastic than this - that buyers are, in a real sense, "captive" in the market - and, therefore, that the monopoly might be rather less benign. Of course, one might make much the same argument in favour of a $5 \%$ or a $15 \%$ threshold level for SSNIP, so this argument does not really take us very far. What it suggests, however, is that if at any stage of the iterative SSNIP procedure one finds a $10 \%$ price rise to be sustainable, one ought to go on and ask the further question: "in that case, just how high a price rise would be sustainable?".

"Small but significant" refers to both the size of the hypothesized price rise, and also (at least implicitly) to how long it is maintained. It is clear that a $10 \%$ price rise that is maintained for about two days is unlikely to induce much substitution one way or the other; on the other hand, a $10 \%$ price rise maintained for two centuries is likely to paint quite a different picture of the market. There is no obvious rule to determine how long a price rise ought to be considered when applying the SSNIP test. In a sense, it depends on how long it will take consumers and suppliers to respond to the price rise (if, of course, they are actually minded to

\footnotetext{
${ }^{10}$ If marginal costs are rising, then a $10 \%$ margin of price over marginal cost implies a rather higher margin of price over average cost, and thus a rather higher gross accounting margin.
} 
respond), and this will differ by type of product and type of consumer. The usual convention here is to suppose that the hypothetical price rise is maintained for a year. Again, it is hard to defend this practice except on the grounds of reasonableness: if it really takes more than a year for consumers to switch to alternative products, or for suppliers to reengineer their product programmes to produce a me-too substitute for the (hypothetically) monopolized product, then the rewards for monopolization are likely to last longer than at least a year, and this seems, somehow, like a long time. The bottom line is that if one finds at any stage of the iterative SSNIP procedure that a 10\% price rise maintained for at least a year is sustainable, one might want to go on and ask the further question: "in that case, just how long would that price rise be sustainable?".

\section{many markets, many market segments}

All firms operate in many markets - labour markets, capital markets, raw material markets and, of course, downstream markets in which they sell their products to consumers. Further, any firm actively interested in increasing it's profits is likely to try to segment it's downstream markets, identifying different groups of consumers with different needs and a different willingness to pay, and serving each with a variant of the basic product that suits their needs and at a different price. The question that this raises is which market should the SSNIP test be applied to, and, in principle, the simple answer is "all of them". In practice, however, some of these markets are likely to be more interesting than others: some will seem to be inherently less likely to be competitive than others, or involve consumers or rival firms whose vulnerability might be a source of concern. Further, anti-trust investigations are typically complaint driven, and this naturally focuses attention on some markets rather than others. Finally, anti-competitive activity in one market (e.g. driving down the prices of inputs paid to suppliers) might well be considered benign if the rents so gained are dissipated through competition in the other markets that the firm in question operates in, leaving consumers in these markets as the ultimate beneficiary of whatever market power is exploited in the monopolized market. This suggests that any investigation into possible monopoly power in particular markets may require a complementary exploration of other markets.

Almost any market one might want to consider is likely to be divisible into a number of market segments, and it is almost always a moot question whether these segments ought to be regarded as markets in and of themselves, or as parts of a broader market. The SSNIP test starts from the narrowest market definition which seems reasonable in the circumstances, and this means that it is likely to lead one to the conclusion that particular segments are separate markets. The problem is that these separate segments are likely to be interdependent - activities which occur in one of them will almost certainly have effects on others. This should not cause a problem in defining the market (although the precise boundaries between segments that are "near" to each other is likely to be difficult to fix with any certainty), but it will make the assessment of the degree of competition in any of them rather more tricky than would otherwise be the case. Thinking of different market segments as being different markets does, however, have one great virtue, and that is that it makes identifying the effects of anti-competitive behaviour much more precise. If there are real differences between different groups of consumers, then a sensible monopolist will not treat them all the same: some will be more vulnerable than others, and will, therefore, bear more of the burden of monopoly than others. Anything that targets the effects of anti-competitive behaviour - and, in doing so, 
identifies just who is adversely affected by it - makes the process of remedying such effects much easier and the design of remedies more effective.

\section{ASSESSING COMPETITIVENESS}

The SSNIP test enables us to identify the relevant market for the purposes of analysis but, as we noted earlier, it is just the start of any anti-trust inquiry. The real issue in every case is not what the market is, but how competitive it is (or how a merger affects competition). There are three features of the market - however defined - which determine it's competitiveness and they are: the degree of intra-market rivalry, the extent of buyer (or supplier) power, and the state of entry. ${ }^{11}$ We consider each briefly in turn.

\section{intra-market rivalry}

The SSNIP test identifies market boundaries by assessing the consequences of the actions of a hypothetical monopolist, but, in practice, the market so identified is unlikely to be completely monopolized. As a consequence, the firms who are at the centre of anti-trust interest in any particular case are likely to face potential competitive challenges from existing rivals producing similar products. Thus, in monopoly cases, whether this group of competitors is able to act collectively and behave as if they were a monopolist is the first and most natural question to ask; in merger cases one needs to ask whether competitors will affectively be able to constrain price increases in the enlarged post-merger firm.

Assessing intra-market rivalry is, of course, a very old chestnut, and there is not enough space to do it any kind of justice here. ${ }^{12}$ The traditional approach to this question is structural, and involves computing market shares in search of "high" levels of concentration or positions of market dominance. There has grown up a set of conventions - some of which have become embodied in statutes - built up around rules of thumb expressed in terms of market shares or levels of market concentration. ${ }^{13}$ As we noted earlier, these rules of thumb -- and this structural approach more generally - have much to commend them as a way of prioritising scarce anti-trust resources or establishing jurisdiction. However, from the point of view of assessing the competitiveness of any particular market, it is probably too simple. It may be that

\footnotetext{
${ }^{11}$ Curiously enough, assessing competitiveness in this way is almost exactly how business strategists assess the "attractiveness" of the market. In particular, Michael Porter's famous "five forces" are: buyers, suppliers, entrants, rivals and substitutes - our classification above lumps buyers and suppliers on the one hand, and rivals and substitutes on the other, together; see Porter (1980).

12 For good overviews of how to assess intra-market rivalry - and more generally, of the economics of anti-trust see Neuman (2001), Harrington et al (2000), and others.

13 One currently used measure of market concentration is the Herfindahl index (the HHI for short), which is defined as the sum of the squares of the market shares of each supplier. For example, if there are five suppliers in a market, each with a share of $20 \%$, the HHI is equal to 2,000 (that is $20^{2}$ which equals 400 times five which equals 2,000). The DoJ uses a rule of thumb which says that an HHI below 1,000 is considered as indicating a low concentration, between 1,000 and 1,800 is considered a moderate level of concentration and over 1,800 highly concentrated. The European Court presumes dominance (in the absence of contrary evidence) for market shares of 50\% and above (Case C62/86 AKZO Chemie BV v Commission (1993) 5 CMLR 215) and the Director General of Fair Trading in the UK uses a threshold of $40 \%$ (see OFT (1999c).
} 
a firm with a large market share will be able to act as a price leader, initiating and then enforcing, high prices. It may also be, however, that the supposed power promised by a high market share will evaporate with use because of the actions of rivals, in which case high market shares identify no more than latent pockets of market power. To understand whether a firm really has market power, one needs to understand how independent of the leader the other firms in the market are, how strong their incentives are to try to take share away from the leader and whether they have the ability to do so. Clearly, this take us beyond the use of simple structural measures of competition, and into an assessment of likely modes of market behaviour. Recent developments involve using richer structural models and evidence to suggest what equilibrium outcomes might be.

\section{buyer (or supplier) power}

The SSNIP test examines buyer substitutability, asking (amongst other things) whether there is an attractive option (i.e. substitute product) open to buyers faced by a unilateral $10 \%$ price rise initiated by a hypothetical monopolist. In fact, buyers not only have "exit" options, they also have "voice" options. In particular, when buyers are small in number and well organized, price setting becomes more like a bargaining process and less like a unilateral posting of prices. The power of buyers (or suppliers) to affect the methods by which prices are set is as important as their ability to exercise exit options. Further, well organized buyers are often in a position to affect the degree of intra-market rivalry, effectively setting one firm against another, or to encourage new entry.

Assessing the strength of buyers (or suppliers) is a delicate issue. The simplest (but still not wholly satisfactory) solution is structural, and involves computing the degree of buyer concentration. The principle here is just the obverse of high market share on the sellers side of the market: a buyer with a large market share swings a large purse, and that will almost certainly enable it to exert some counterveiling power on would be monopolists. More subtle analyses would almost certainly examine the strengths of buyers "exit" options by looking at switching costs and trying to ascertain the extent to which they are locked into a particular seller. More broadly, it is important to assess the degree to which buyers can act strategically: that is, to assess their ability to upset collusive arrangements, encourage entry, stimulate innovations which redefine the market and, in the limit, vertically integrate upstream (or downstream in the case of suppliers). As with intra-market rivalry, this takes us well beyond the computation of buyer market shares and into the murky area of behaviour, potential and actual.

entry

Rivals do not actually have to be present in a market to exert an effect on the degree of competition in that market. The threat of entry may, in some circumstances, discipline the behaviour of firms who might otherwise enjoy monopoly power. Failing that, the fact of entry may soon correct any monopolistically induced distortions which might result from the exercise of market power.

To assess the likelihood of entry in any circumstance, one needs, in effect, to produce a business plan that a reasonably efficient entrant might use to commence operations. The comparison between this plan and the actual operations of the incumbent help to establish the margin that incumbents can raise price above costs without losing market share; i.e. without inducing entry. In effect, this is tantamount to measuring the height of entry barriers. In 
practice, however, an actual entrant is likely to incur a number of transitory costs which will fall away when it finally establishes itself in the market. This, in turn, means that one may have to compute not only the height of entry barriers but also assess the ability of the entrant to finance it's operations until it has managed to get control of the short term or transitory costs incurred during the early phases of its entry into the market. Further, since entry is risky and often leads to exit, any exit barriers (like the need to incur large sunk costs) that a failed entrant may have to incur are likely to diminish his/her willingness to enter.

There are, perhaps, two observations worth making about assessing the competitive discipline imposed by entry into markets. The first is that entry and supply side substitutability are very similar. The difference between a supply side substitute (i.e. a rival producer producing a me-too product to compete with the hypothetical monopolist) and an entrant is that the former is able to enter and compete with the hypothetical monopolist within a year. That is, entry is in effect distinguished from intra-market rivalry by the time period in which it occurs. The second observation arises from the fact that entry does not actually need to occur to have an effect on incumbents behaviour. This, in turn, means that it is the perception of a threat of entry which matters as much, perhaps, as the actual fact of entry. Beauty, as they say, is in the eyes of the beholder.

\section{SOME FINAL REFLECTIONS}

There is nothing immutable about market boundaries, and as tastes and technology change over time, so do the contours of particular markets. Indeed, innovation blurs industrial boundaries, and it sometimes induces convergence between what were once seemingly quite independent markets. As process innovations affect the supply side of a market, or product innovations affect demand, so the nature of substitution between particular products -- that is, the "how much" and "how fast" response to a hypothetical 10\% price rise - also changes. And, such changes also affect the competitiveness of markets, however they are defined. Changes in technology alter entry barriers, and affect the strategic position of particular buyers or suppliers. All of this makes the analysis of market boundaries much harder than it might otherwise be, but it changes relatively little in principle. The SSNIP test is still the right way to think about identifying market boundaries, even if the result of applying it to a particular market in one year is likely to differ from the results obtained by doing the same test in the same market a year or two later. Further, the same basic drivers of competition - intra-industry rivalry, buyers/suppliers and entry - all apply in principle, even if a new technology alters the particular effects that they have in practice.

The real complication comes because technological changes are not wholly exogenous. Firms make conscious decisions to invest in R\&D, or to introduce new products or adopt new innovations introduced by other firms. Amongst other things, this means that the market boundaries that one is likely to observe in any one year will depend on decisions made by firms in past years. Firms that have favourable market positions in the past are likely to introduce those innovations which help to reinforce or protect those positions; innovations that disrupt existing market boundaries are more likely to be introduced by entrants or fringe players who have little to lose - and everything to gain - from a change in market boundaries. Again, this does not in principle affect how one ought to go about identifying market boundaries, but it does mean that forming expectations about how likely existing boundaries are to change - and in what direction - is more speculative than it might otherwise be. 
Of course, firms that make investments in $R \& D$ compete with other firms who also choose to invest in R\&D. Such investments affect both costs as well as the product quality/diversity available to consumers. Indeed, some people believe that quality and diversity of choice are likely to be more important determinants of welfare than high prices, and for those who think in this way, the important market whose competitiveness needs to be assessed is that in which R\&D competition occurs (sometimes called "the innovation market"). ${ }^{14}$ What makes this an interesting complement to normal product market analyses is that the forces of competition - and, indeed, the identity of the competitors - in the innovation markets that a firm compete in may well differ from those which are found in the product markets where it sells it's products. At the end of the day, however, markets are the stage on which competition occurs, and the fact that firms compete in several interrelated markets - indeed, the fact that firms consciously try to shape the competitive structure of the markets that they operate in does not in any way diminish the importance of trying to establish the exact contours of those markets, or of assessing their competitiveness.

\footnotetext{
${ }^{14}$ See Gilbert and Sunshine (1995) and Rapp (1995) for differing views on the usefulness of analysing such "innovation markets"
} 
Profits before hand (denoted with subscript 0 ) are equal to revenue (price $(\mathrm{P})$ times quantity (Q)) minus total costs (average cost (C) times quantity):

(1) $\Pi_{0}=\left(P_{0}-C_{0}\right) Q_{0}$

A change in price $\Delta P=P_{1}-P_{0}$ leads to a change in quantity demanded $\Delta Q=Q_{1}-Q_{0}$ and may also lead to a change in the average cost of production $\Delta C=C_{1}-C_{0}$. This gives a new level of profits:

(2) $\quad \Pi_{1}=\left(P_{1}-C_{1}\right) Q_{1}$

The change in profits is given by:

$$
\Delta \Pi=\Pi_{1}-\Pi_{2}=\left(P_{1}-C_{1}\right) Q_{1}-\left(P_{0}-C_{0}\right) Q_{0}
$$

$$
=\Delta P Q_{1}+\left(P_{0}-C_{0}\right) \Delta Q-Q_{1} \Delta C \text {. }
$$

Note that when $\Delta P>0$ we expect that $\Delta Q<0$. We are interested in looking at when $\Delta \Pi$ will be less than zero. It is convenient to rewrite (3) by dividing through by $P_{0}$ (note that this does not matter as $\Delta \Pi<0$ if $\left.\Delta \Pi / P_{0}<0\right)$, yielding

(4) $\frac{\Delta \Pi}{P_{0}}=\frac{\Delta P}{P_{0}} Q_{1}+\frac{P_{0}-C_{0}}{P_{0}} \Delta Q-\frac{Q_{1}}{P_{0}} \Delta C$.

Note that $\Delta P / P_{0}$ is the hypothetical price rise (usually considered to be 10 per cent).

Begin by considering the case where average cost is constant (it does not depend on the amount produced) so that $\Delta C=0$. Then,

(5) $\frac{\Delta \Pi}{P_{0}}=\frac{\Delta P}{P_{0}} Q_{1}+\frac{P_{0}-C_{0}}{P_{0}} \Delta Q$.

Thus, a price rise will be profitable if:

(6) $\frac{\Delta P}{P_{0}} Q_{1}>\frac{P_{0}-C_{0}}{P_{0}} \Delta Q$; 
that is if the increased price charged on the new (lesser) quantity is greater than the lost margin on the decrease in quantity. If there are economies of scale, then we also need to work out $\frac{Q_{1}}{P_{0}} \Delta C$. If, for example, $\Delta \mathrm{C}>0$ when $\Delta \mathrm{Q}<0$, the increase in price on the new quantity needs to be greater than the lost margin on the decreased quantity plus the higher costs on the new quantity. 


\section{REFERENCES}

Baker, J. and T. Bresnahan (1985) "The Gains from Merger of Collusion in Product Differentiated Industries", Journal of Industrial Economics, 33, 427 - 44.

Baker, J and Rubinfeld, D (1999) "Empirical methods in antitrust litigation: review and critique" American Law and Econmics Review V1 N1/2, 386-425

Competition Commission (2002) "Economic Guidance" (available from the website)

EC (1997) Notice on the definition of the relevant market for the purposes of community competition law, OJ C372, 09/12/97.

Elzinga, K. and T. Hogarty (1973) "The Problem of Geographical Market Definition”, Antitrust Bulletin, 18, $45-81$.

Fisher, F. (1987) "Horizontal mergers: Triage and Treatment", Jopurnal of Economic Perspectives, 40, 23 - 40.

Forni, M (2002) "Using Stationarity Tests in Antitrust Market Definition" CEPR Working Paper 3236.

Geroski, P. (1998) “Thinking Creatively About Markets”, International Journal of Industrial Organization, 16, $677-96$.

Gilbert, R. and D. Sunshine (1995) "Incorporating Dynamic Efficiency Concerns in Merger Analysis”, Antitrust Law Journal, 63, 509 - 597.

Hausman, J, G Leonard and C Vellturo (1996) "Market definition under price discrimination" Antitrust Law Journal, 64, 367-386

Harrington, J. et al (2000) Economics of Regulation and Antitrust, MIT Press, Cambrdige Mass.

Kovacic, W (1997) "Administrative adjudication and the use of new economic approaches in antitrust analysis", George Mason Legal Review, Vol 5:3, 313-320

Neuman, M. (2001) Competition Policy, Edward Elgar, Cheltenham, UK

OFT (1999a) Quantitative techniques in competition analysis, OFT Research Paper 266.

OFT (1999b) Market Definition, OFT Working Paper 403.

OFT (1996c) Assessment of Market Power, OFT Working Paper 415.

OFT (2001) "The role of market definition in monopoly and dominance inquiries: A report prepared for the OFT by NERA", OFT Economic Discussion Paper 2.

Porter, M. (1980) Competitive Strategy. Free Press, New York 
Rapp, R. (1995) “The Misapplication of the Innovation Market Approach to Merger Analysis", Antiturst Law Journal, 64, 19 - 47.

Sheffman, D. and P. Spiller (1987) "Geographical market Definition Under the USDOJ Merger Guidelines", Journal of Law and Economics, 30, 123 - 47.

Slade, M. (1986) "Exogeneity Tests of Market Boundaries Applied to Petroleum Products", Journal of Industrial Economics, 34, 291 - 304.

Steen, F and K.G. Salvanes (1999) "Testing for market power using a dynamic oligopoly model” International Journal of Industrial Organisation, 17, 147-177.

USDOJ (1992) Horizontal Merger Guidelines, www.ftc.gov/bc/docs/horizmer.htm 